\title{
Solid-Phase Synthesis of Aza-Lysine Peptide Analogue of Trypsin Substrate
}

\author{
Mariam Traoré and William D. Lubell \\ Département de Chimie, Université de Montréal, C.P. 6128, Succursale Centre-Ville, \\ Montréal, QC, H3C 3J7, Canada
}

\section{Introduction}

Lysine residues play critical roles in biological processes, such as protein post-translational modifications, enzymatic cleavage, and cell penetration. Constrained Lys residues may thus serve as tools for studying the structural requirements for such phenomenon. Azapeptides contain semicarbazide residues that may favor turn geometry, enhance molecular recognition and prevent protease degradation [1]. We have developed general methods for inserting aza-lysine residues and various side chain derivatives anywhere within a peptide sequence (Figure 1) [2-4].
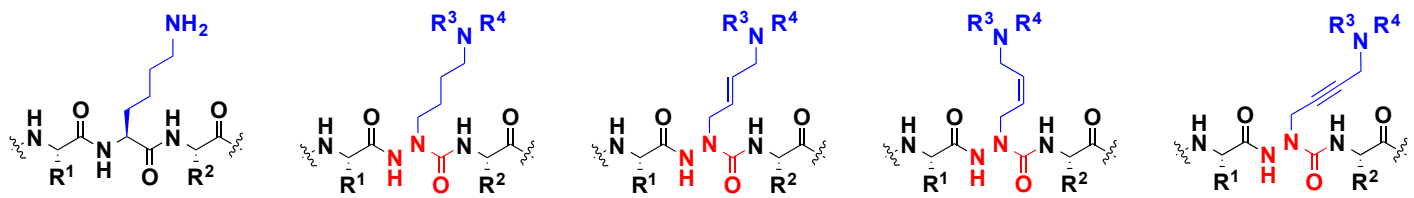

Fig. 1. To study the role of Lys residues (left) in peptides, aza-lysine residues possessing different amine and alkyl side chains have been prepared [2,3].

\section{Results and Discussion}

Trypsin is a serine protease that normally cleaves peptides at the carboxyl terminal of Lys and Arg residues. Trypsin is involved in cell growth, cell death, and immune defense. Imbalanced trypsin activity has been implicated in ovarian, colorectal and pancreatic cancers [5]. Azapeptides have previously been studied as tools for modulalting trypsin activity. For example, the azatripeptide BocLys-azaPhe-Leu was examined as a trypsin substrate [6]. In comparison with the parent peptide BocLys-Phe-Leu, the azapeptide counterpart was digested more rapidly [6]. Complete cleavage to form the azaPhe-Leu and Phe-Leu dipeptides were respectively observed after $24 \mathrm{~h}$ and $48 \mathrm{~h}$. Considering that semicarbazides may serve as better leaving groups, we plan to examine a trypsin substrate in which the Lys residue itself is replaced by azaLys.

The tetrapeptide Fmoc-Ser-Ala-Lys-Gly- $\mathrm{NH}_{2}$ was studied, because of its relationship to the previously synthesized substrate Fmoc-Ser-Pro-Arg-Gly [7] that could be monitored effectively in trypsin digestion experiments. To study the influence of aza-residues on trypsin cleavage, we have now synthesized Fmoc-Ser-Ala-azaLys-Gly (1) on Rink amide resin (Scheme 1). Semicarbazone resin 3 was obtained after Fmoc deprotection from Rink amide resin using a solution of $20 \%$ piperidine in DMF. Acylation of the amine resin with 4-nitrophenyl 2-(diphenylmethylidene)carbazate, which was prepared from the reaction of benzophenone hydrazone with p-nitrophenylchloroformate, gave semicarbazone resin 3, which was alkylated with 1-bromo-4-chlorobutane (320 mol \%) employing tetraethylammonium hydroxide (300 mol \%, of a $40 \%$ aqueous solution) as base in THF for $2 \mathrm{~h}$ at room temperature to provide the chloroalkyl semicarbazone 4. Chloride displacement with sodium azide $(600 \mathrm{~mol} \%)$ in DMF at $60^{\circ} \mathrm{C}$ for $12 \mathrm{~h}$ provided dipeptide resin $\mathbf{5}$. The semicarbazone protecting group was removed using a $1.5 \mathrm{M}$ solution of hydroxylamine hydrochloride in pyridine, and the resulting semicarbazide $\mathbf{6}$ was coupled to Fmoc-Ala by using diisopropylcarbodiimide (DIC) to provide azatripeptide 7, which after Fmoc removal, was coupled to Fmoc-Ser(tBu) using HBTU (300 mol\%) and DIEA $(600 \mathrm{~mol} \%)$. Azide was reduced with tris(2-carboxy)ethylphosphine (TCEP) $(300 \mathrm{~mol} \%)$ in $\mathrm{THF} / \mathrm{H}_{2} \mathrm{O}(9 / 1)$ for $12 \mathrm{~h}$ to provide the corresponding amine 8. After cleavage from resin using TFA/ $\mathrm{H}_{2} \mathrm{O} / \mathrm{TES}$ (9.5:0.25:0.25), tetrapeptide 1 (86\% crude purity) was purified by HPLC on a C18-column and isolated in 4\% overall yield and >98\% purity: LCMS [20-50\% MeOH (1\% FA) in water $(1 \% \mathrm{FA})$ over $12 \mathrm{~min}] \mathrm{RT}=7.7 \mathrm{~min}$. 

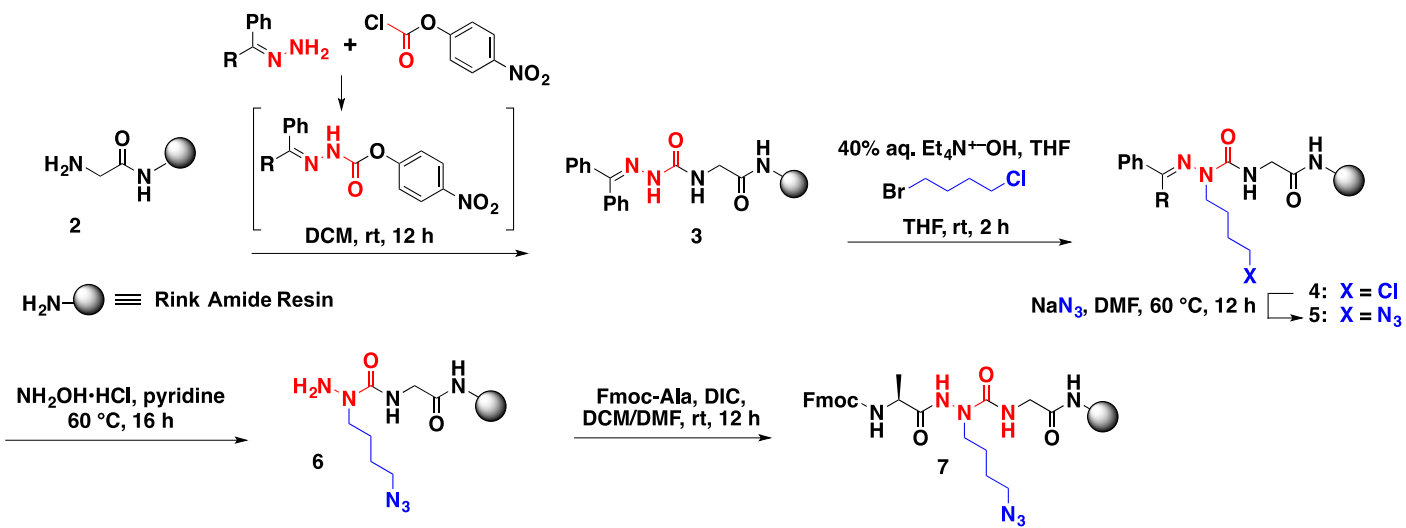

1) $20 \%$ Piperidine, 2) Fmoc-Ser(Ot-Bu), HBTU, DIEA, DM 3) $\mathrm{P}\left(\mathrm{C}_{2} \mathrm{H}_{4} \mathrm{CO}_{2} \mathrm{H}\right)_{3}, \mathrm{THF} / \mathrm{H}_{2} \mathrm{O}(9: 1), 12 \mathrm{~h}$
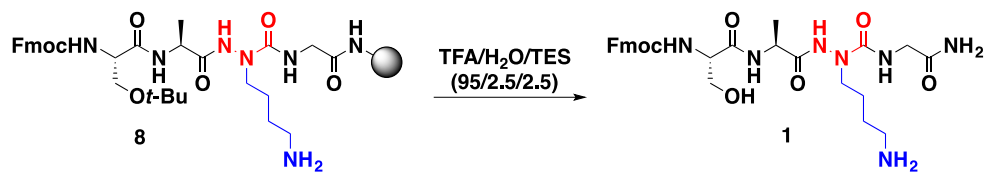

Scheme 1. Synthesis of trypsin substrate analogue, Aza-Lys peptide 1.

Efficient methods were developed for making azapeptides bearing aza-lysine residues, and were employed in the synthesis of an aza-analog of a trypsin substrate. This synthetic method and azapeptides bearing aza-amino acid residues, such as aza-Lys and aza-Arg, should find interesting applications for studying other peptides, particularly those involved in protein post-translational modifications and in cell-penetration processes.

\section{Acknowledgments}

This research was supported by the Natural Sciences and Engineering Research Council of Canada (NSERC), the Ministère du développement économique de l'innovation et de l'exportation du Québec (\#878-2012, Traitement de la dégénerescence maculaire) and Amorchem.

\section{References}

1. Proulx, C., Sabatino, D., Hopewell, R., Spiegel, J., Garcia-Ramos, Y., Lubell, W.D. Future Med. Chem. 3, 1139-1164 (2011), http://dx.doi.org/10.4155/fmc.11.74

2 Traore, M., Doan, N.-D., Lubell, W.D. Org. Lett. 16, 3588-3591 (2014), http://dx.doi.org/10.1021/ol501586y

3. Zhang, J., Proulx, C., Tomberg, A., Lubell, W.D. Org. Lett. 16, 298-301 (2014), http://dx.doi.org/10.1021/ol403297v

4. Doan, N.-D., Zhang, J., Traore, M., Kamdem, W., Lubell, W.D. J. Pept. Sci. 21, 387-391 (2015), http://dx.doi.org/10.1002/psc. 2711

5. Goldberg, D.M. Clin. Chim. Acta 291, 201-221 (2000), http://dx.doi.org/10.1016/S0009-8981(99)00229-6

6. Dutta, A.S., Giles, M.B. J. Chem. Soc. Perkin 1, 244-248 (1976), http://dx.doi.org/10.1039/P19760000244

7. Adjemian, J., Anne, A., Cauet, G., Demaille, C. Langmuir 26, 10347-10356 (2010),

http://dx.doi.org/10.1021/la100397g 